\title{
Ilha do Medo: proposta de uma nova opção de produto turístico para a cidade de São Luís (MA)
}

\author{
Ilha do Medo: proposal of a new tourism product option for the \\ city of São Luís (MA, Brazil)
}

Saulo Ribeiro dos Santos, Paloma Araújo Pinto, Protásio Cézar dos Santos

\begin{abstract}
RESUMO
O estudo apresenta uma proposta de um novo produto turístico (Ilha do Medo) para a cidade de São Luís (MA), ressaltando a inserção de melhorias para que assim, o mesmo possa ser inserido no portfólio oferecido pela atividade, assim como suas peculiaridades e a interação entre as diversas variáveis que a integram. Como metodologia de desenvolvimento da pesquisa, utilizou-se a bibliográfica e a documental, além de observação direta e visitas in loco, que resultaram em diagnóstico e avaliação das condições do atrativo. Avaliou-se a necessidade de planejamento do turismo, com ênfase no turismo comunitário como uma maneira de qualificar o atrativo a ser formatado a nível local além da metodologia do processo de planejamento. Como resultado, apresenta-se uma proposta inovadora para o atrativo, como nova opção de produto turístico para São Luís.
\end{abstract}

PALAVRAS-CHAVE: Produto Turístico; Ilha do Medo; Planejamento Turístico.

\section{ABSTRACT}

The study presents a proposal for a new tourism product (Ilha do Medo) for the city of São Luís (MA, Brazil), emphasizing the inclusion of improvements to it so it can be inserted into the portfolio offered by the activity, as well as its peculiarities and the interaction between the variables belonging to it. The methodology of research development, we used the literature and documents, direct observation and site visits, which resulted in the diagnosis and assessment of the conditions of the appeal. Assesses the need for tourism planning, with emphasis on community tourism as a way to qualify the appeal to be formatted at the local level beyond the methodology of the planning process. As a result, we present an innovative proposal for attractive option as a new tourism product for São Luís.

KEYWORDS: Tourism Product; Ilha do Medo; Tourism Planning. 


\section{Introdução}

As perspectivas em torno da atividade turística são otimistas e refletem sua relevância como fator de desenvolvimento socioeconômico das regiões. Economicamente está entre as cinco maiores atividades econômica do mundo, gerando milhares de empregos, elevando o Produto Interno Bruto (PIB) das localidades e proporcionando investimentos de capital. Os benefícios econômicos gerados em torno dos recursos turísticos dos destinos chamam atenção pelo nível de contribuição à economia local e à capacidade que detêm de induzir o desenvolvimento econômico e promover melhorias na qualidade de vida das comunidades.

No entanto, apesar dessas vantagens, sua gestão eficiente e adequada, bem como a consecução dos seus benefícios, torna-se um desafio às localidades que dispõem de potencial turístico, pois, o turismo é uma atividade que interfere em uma série de aspectos e sua exploração necessita de estudos criteriosos e de medidas que regulamentem sua utilização. A exploração do turismo enquanto atividade econômica, da mesma forma, não deve abster-se de critérios e normas que norteiem seu desenvolvimento e que considere a integração dos aspectos econômicos aos demais aspectos envolvidos.

O planejamento turístico, assim, apresenta-se como um instrumento que integra estudos, normas e métodos racionais capazes de desenvolver o turismo e garantir seus benefícios quando bem executado e acompanhado. Além disso, possibilita às localidades a construção de um turismo competitivo e com maiores oportunidades de crescimento.

Nesse sentido, aborda-se as relações entre potencial turístico a nível municipal, através de estudos de atrativos de possíveis formatações de produtos para a cidade de São Luís (MA), afim de produzir uma maior competitividade entre os produtos presentes no portfólio oferecido pela mesma. Portanto, objetiva-se propor uma nova opção de um produto turístico para a cidade de São Luís (MA), focando-se em um atrativo turístico sob as perspectivas e recomendações do planejamento e projeto turístico.

Os meios metodológicos utilizados foram a pesquisa exploratória e descritiva, na qual se utilizam dados teóricos para alcançar os objetivos. Adota-se ainda uma abordagem multidisciplinar, uma vez que o tema trabalhado compreende várias áreas do conhecimento, ou seja, história, geografia, economia e administração, que se tornam essenciais à sua compreensão e interpretação. Além disso, elabora-se uma proposta para o atrativo turístico, mostrando-se uma concepção dinâmica e reflexiva das variáveis relacionadas.

A pesquisa enquadra-se também, como bibliográfica, dando todo um suporte teórico ao tema, e ao lado desta, a pesquisa de campo, onde se coletou dados junto aos órgãos públicos e instituições responsáveis pela atividade turística da localidade, além da realização de entrevistas informais moradores, relacionados ao atrativo turístico.

Justifica-se a importância da pesquisa para a apresentação de proposta de um novo produto turístico para a cidade de São Luís, com o intuito de impulsionar a atividade e os roteiros turísticos, através de uma 
opção diferenciada, com planejamento e gestão, indicados pelos princípios da segmentação turística.

\section{Turismo: concepções e atualidades}

O turismo, atualmente, é um dos fenômenos mais importantes do ponto de vista político, econômico, ambiental e sociocultural. Pois, deixou de ser visto apenas como um sinônimo de lazer e passou a assumir um papel de agente social nas sociedades em que se desenvolve (MARUJO, 2008).

Nesse aspecto, pondera-se que o mesmo é um fenômeno e que deve ser estudado e analisado sob a luz das ciências sociais, devido a sua extensão ir além das questões ligadas à economia, à política e à cultura de uma sociedade, ligando-se à experiência de cada pessoa que se envolve ou pratica o turismo.

Hoje com o desenvolvimento dos meios de transportes, com a globalização e uma maior renda e tempo livre por parte dos cidadãos comuns, a preocupação destes com a obtenção de cultura e bem estar, faz com que o turismo desponte como setor econômico de maior potencial de crescimento no mundo.

As pessoas começam a sentir a necessidade de conhecer novos lugares e culturas, de viajar e especialmente com o intuito de descanso. $O$ turismo inicia seu desenvolvimento e sua consolidação como um dos "objetos de consumo mais desejados da população desse novo século" (CAMPOS, 2005, p.26).

Por ser considerado um impulsionador da economia, movimentar grande quantia e ser uma atividade enérgica, o turismo é dependente de algumas estruturas para que torne a atividade turística real, como infraestrutura básica, hospitais, hoteleiras, principalmente, transportes que vêm impulsionando cada vez mais a atividade, por sua acessibilidade de usuários.

Segundo Trigo (1993, p.17), "os fatores que levaram ao desenvolvimento do turismo nestas últimas três décadas foram os mesmos que transformaram profundamente o planeta, seja no âmbito das relações econômicas e políticas, seja no das relações sociais e culturais".

O turismo vem conquistando um espaço cada vez maior na sociedade, por ser uma atividade que está em pleno crescimento (OMT, 2011). Além disso, a atividade turística induz e compreende uma série de aspectos e relações específicas que, devido à complexidade que lhes são inerentes, merecem um estudo analítico e que abranja suas características. De acordo com os dados OMT (2011), entre 2000 e 2008, as viagens internacionais cresceram 4,2\% ao ano, alcançando o total de 922 milhões de turistas em 2008, gerando uma renda de aproximadamente US\$ 5 trilhões.

Percebe-se a descentralização do turismo na Europa para as demais regiões do planeta, principalmente a Ásia, que foi um dos continentes que mais investiu em equipamentos turísticos nos últimos anos. 
Entendendo a oferta turística como tudo o que é oferecido para os visitantes, é possível identificar, segundo Goeldner, Ritchie e Mclntosh (2002), quatro categorias que a compõem e que juntas oferecem diferencial da localidade ou região:

a) Recursos e ambientes naturais: clima, flora, fauna, relevo, praias entre outros atrativos da região;

b) O ambiente construído: neste tópico estão pautadas a infraestrutura e a superestrutura, construções voltadas para dar suporte aos turistas, produção coligada ao turismo e outros;

c) Transporte: é a disponibilidade de transporte para o visitante, da origem até o destino e dentro do próprio destino, incluindo aviões e voos, taxis, trens, navios, automóveis e outros elementos que permitam a visitação;

d) Hospitalidade e recursos culturais: são temas incluídos à cultura local do destino, como idiomas, crenças, costumes e conduta de trabalho e lazer, a amabilidade, amizade e vontade de receber bem dos residentes daquela localidade.

Portanto, a oferta turística é tudo que está à disponibilidade do turista, sendo mesclada dos múltiplos produtos turísticos de uma localidade, e obrigatoriamente, está organizada para ser proporcionada e gerar experiências positivas para um visitante com demandas específicas.

Diferentemente da oferta turística, que tem o produto como responsável pela realização da oferta turística, o principal agente econômico responsável pela demanda turística é o consumidor de produtos turísticos ou, simplesmente, o turista ou usuário de produtos turísticos.

Segundo Dias (2005), a demanda turística é o conjunto de turistas, que de forma individual ou coletiva, estão motivados a consumir uma série de produtos ou serviços turísticos com o objetivo de cobrir suas necessidades de descanso, recreação, entretenimento e cultura em seu período de férias.

A demanda turística é, portanto, real, em relação ao número de pessoas que viaja, e potencial, pelo número de pessoas que deseja viajar para usufruir de produtos e serviços turísticos, além de vivenciar novas experiências turísticas.

O que se pode concluir é que a demanda turística está vinculada a diversos fatores, alguns relativos às preferências e motivações dos visitantes, e outros atrelados a aspectos relacionados aos microambientes e ao mercado do qual o destino turístico faz parte.

A segmentação de mercado veio como uma importante ferramenta que passou a existir no mercado para aquecer a conquista, a criação de necessidades e desejos no cliente, assim, instituições públicas ou privadas, como empresas ou organizações ligadas à atividade turística estão procurando os caminhos que atendam aos mais variados públicos, muitas vezes utilizando-se do conceito e das características da segmentação de mercado. 
De acordo com o Ministério do Turismo (MTUR), a segmentação é entendida como uma forma de organizar o turismo para fins de planejamento, gestão e mercado. Os segmentos turísticos podem ser estabelecidos a partir dos elementos de identidade da oferta e também das características e variáveis da demanda. (BRASIL, 2010).

Os visitantes que consomem os produtos turísticos podem ser divididos por categorias, a partir das várias grandezas que os envolve, como as questões geográficas, demografia, o uso que fazem do produto, e sua psicografia (BRASIL, 2010).

A partir da escolha de um público por um segmento, a estruturação de produtos e a elaboração de roteiros, a escolha é encaminhada para que ocorra seu o desenvolvimento, pois a identidade dada a cada roteiro será criada através do levantamento feito sob a consideração que o público se destina.

O consumidor passou a visar o diferente, o novo, o que julga original, e o turista abrange esse aspecto com domínio, pois segundo Waimberg (2003) o turismo é o fenômeno da diferença, ou seja, é a diferença o principal agente motivador dos deslocamentos turísticos.

Para atender as necessidades específicas, o mercado turístico vem se segmentando cada vez mais, formatando novos tipos de turismo, criando roteiros temáticos, adaptando produtos e serviços de acordo com as especificidades, desejos, limitações e necessidades dos clientes turistas.

A segmentação com base na oferta define o tipo de turismo que será oferecido ao visitante. A definição desses tipos de turismo é realizada a partir da existência de certas características comuns em um território, que segundo o MTUR (BRASIL, 2010), são:

a)aspectos e características comuns (geográficas, históricas, arquitetônicas, urbanísticas, sociais);

b)atividades, práticas e tradições comuns (esportivas, agropecuárias, de pesca, manifestações culturais, manifestações de fé);

c)serviços e infraestrutura comuns (serviços públicos, meios de hospedagem e de lazer).

Percebe-se que as características necessárias para o turismo em uma localidade, se torna, também, uma forma de tríplice característica para formatar com sucesso uma localidade, pois com os atrativos e a cultura, se o local possuir serviços, infraestrutura adequada, possivelmente, o turismo conseguirá se destacar como uma atividade econômica importante na localidade.

\section{Atrativo e produto turístico}

Entende-se como atrativo turístico todo lugar, objeto ou acontecimento de interesse para o turismo ou de acordo com Cerro (1992), estabelece a relação do principal componente e mais importante do produto turístico, pois produz a seleção, por parte do turista, do local de destino de uma viagem, ou 
seja, determina um fluxo turístico até a localidade. Os atrativos turísticos podem ser naturais, culturais, manifestações e usos tradicionais e populares, realizações técnicas e científicas contemporâneas e acontecimentos programados.

A partir das definições dispostas anteriormente, pode-se afirmar que o atrativo turístico tem por desígnio o ato de atrair, como derivado de atrativo, os grupos humanos para um determinado local. Lugar este que engloba as características e funções de que necessitam os grupos humanos à sua vivência (DIAS, 2005), sendo assim, os atrativos de cada lugar devem satisfazer às necessidades e desejos naturais que os visitantes têm do movimento.

Os autores analisam que o atrativo é fundamental, mas que sem planejamento não há como atender as exigências dos turistas, e também, é importante analisar a situação atual para os autóctones, de forma, que a partir do momento, que o atrativo é estruturado, não venha afetar ou impactar negativamente 0 atrativo e o cotidiano dos moradores.

Por isso, Piperoglou (1967, p.169) esclarece que são necessárias quatro etapas na avaliação do desenvolvimento de um atrativo turístico:

a) investigação do mercado para descobrir as preferências e as necessidades dos turistas;

b) identificação dos elementos buscados pelos turistas na área de estudo;

c) definição da região em termos de interação espacial dos recursos;

d) estudo da capacidade de absorção de visitantes pela região, do ponto de vista espacial e humano.

Portanto, o organizador e planejador do turismo deve possuir conhecimento profundo e saber utilizar as estratégias de marketing para então atrair os visitantes.

Mediante estes aspectos o atrativo estará preparado para atender as exigências e necessidades dos turistas, fazendo com que desperte a qualidade da experiência recebida pelo mesmo, o que consequentemente aumentará a satisfação.

A atividade turística se torna, ao passar do tempo, cada vez mais complexa, no sentido de desvendar as necessidades e desejos do consumidor da atividade, pois, de acordo com o que foi visto anteriormente, os desejos e necessidades passaram a depender de mais características ou fatores internos e externos que influenciam na sua escolha de destino.

Panosso Netto e Gaeta (2010, p.16) afirmam que "o consumidor do turismo e o contexto no qual se integra apresentam, atualmente, características que favorecem a experiência e nos levam a pensar na autenticidade dos produtos e serviços".

Uma multiplicidade de bens e serviços oriundas do consumo e satisfação das motivações é gerada pela atividade turística, além de anseios e necessidades dos visitantes, que buscam cada vez mais produtos e 
serviços de qualidade para atender suas exigências, conforme comentado anteriormente (BRASIL, 2010).

Contudo, determinar quais são os bens e serviços passíveis de tal consumo turístico, torna-se uma empreitada perturbadora, lembra-se que existem produtos que, criados para a população local, são consumidos pelos turistas, assim como existem produtos que são criados com o objetivo de atender a entrada de turistas, mas podem, igualmente, satisfazer as necessidades da população local.

A produção no turismo é determinada através dos bens e serviços congregados a outros fatores oriundos da atividade. A produção no turismo é, assim, uma conciliação de produtos ou, de acordo com Cunha (1997), o conjunto dos elementos que, podendo ser comercializado, direta ou indiretamente, motiva as deslocações, gerando uma procura. Os visitantes são atraídos pelas produções turísticas de uma diversidade de destinos que competem entre si para abrigar, ao máximo, elementos que façam parte das motivações turísticas.

As características da produção no turismo são dotadas de personalidade própria, diferenciada de outras produções, pois, se desenvolve de maneira peculiar e aborda aspectos não encontrados em outras atividades, muito embora enfrente os mesmos problemas de escassez de recursos presentes em outras produções.

Dentre os aspectos destacados pelo Ministério, é possível a formulação de produtos que sejam interessantes do ponto de vista do turismo. De acordo com Ignarra (2003, p.50) o produto turístico é formado por seis componentes: "bens, serviços, serviços auxiliares; recursos; infraestrutura e equipamentos; gestão; imagem da marca; e preço".

Assim, os bens e serviços são a matéria-prima para o desenvolvimento da atividade turística e são compostos por: produtos de alimentação, materiais esportivos e de limpeza, serviços em geral (receptivo, hospitalidade, informação etc.). Já os serviços auxiliares complementam estes últimos e são formados por: viagem, alojamento, alimentação, atrações, comércio, indústria, lavanderias, livrarias, cinemas, locadoras de veículos, guias de turismo, organizadores de eventos, dentre outros (IGNARRA, 2003).

\section{Planejamento e projeto turístico}

No planejamento turístico, as leis necessárias para o desenvolvimento de infraestrutura básica destinada ao bem estar do turista e também da população local, que os recebe, é de "responsabilidade do Estado, assim como a conservação, proteção e preservação do patrimônio ambiental, seja ele natural, cultural e psicossocial' (RUSCHMANN 1999, p.84).

Para um bom resultado do planejamento de turismo, o mesmo deve envolver mão de obra especializada, capaz de realizar os passos do processo, tais como a investigação e estudo de casos, definir as políticas e processos de implementação do programa, prever os recursos orçamentários e de pessoal, elaborar a escala metodológica de execução das tarefas, administrar a realização das tarefas e obras, fazer a revisão constante do 
processo e refazê-lo quando necessário. Por estas múltiplas tarefas, o planejamento deve ser realizado por uma equipe envolvendo capacidades técnicas e administrativas específicas da área (BRASIL, 2010).

Nesse sentido, torna-se relevante verificar a visão de Ruschmann (1999), que relata que o planejamento turístico pode abranger os níveis internacional, nacional, regional e local, devendo ser observadas as regiões geograficamente homogêneas e não os limites político-administrativos, como por exemplo, a região amazônica que envolve estados brasileiros e países da América do Sul, ou das Cataratas do Iguaçu que envolvem o Brasil e a Argentina.

$\mathrm{Na}$ elaboração do planejamento é recomendada a assinatura de acordos que definam a manutenção e preservação dos recursos turísticos. Ao tratar dos níveis de planejamento, Ruschmann (1999) nomeia que no nível local o planejamento deve legitimar, entre outras coisas, as zonas industriais e de comércio.

Influenciado, principalmente, pelas transformações advindas da globalização econômica, o mundo vem passando por densas e aceleradas transformações no âmbito social, econômico e cultural, além das redefinições geopolíticas e do avanço científico e tecnológico. Como consequência, ocorre 0 aumento da concorrência nos setores julgados como empresariais.

A partir desse panorama, determinados fatores categóricos ou exigenciais para o sucesso se destacam: a agilidade, a capacidade de adaptação, o poder de inovar de forma rápida e eficiente, e o potencial de aprimoramento contínuo sob grandes restrições de recursos (PROMON, 2011).

Contrapondo a essas declarações, fortalecem-se os sistemas de gerenciamento de projetos, como forma de administrar os empreendimentos transitórios, únicos e multifuncionais, que caracterizam o processo de implementação de estratégias, inovação, adequação e aperfeiçoamento.

Boullón (2002) define projeto turístico como qualquer atividade humana que se desenvolve no momento atual, presente, visando uma consequência no futuro, utilizando a capacidade humana de previsão de possíveis resultados de suas ações, que podem ser vinculadas a princípios ideológicos ou práticos à questões mais complexas vinculadas a soluções de problemas operacionais.

Sobre a origem de ideias geradoras de projetos, não há uma tática determinante para a consagração da mesma, que pode vir espontaneamente ou, ainda como uma consequência de um plano.

\section{A llha do Medo}

A Ilha do Medo (Figura 1) localiza-se a Noroeste da llha de São Luís, e um pouco mais que seis quilômetros de distância do bairro da Praia Grande, onde se localiza o Centro Histórico da cidade, esta é uma das várias outras ilhas que compõem o Golfão Maranhense. 
Chega-se à llha, somente através de via marítima, com embarcações de pequeno porte, como canoas, igarités, jangadas, catamarãs, entre outras. As saídas de tais embarcações se dão através dos portos de pequeno porte, como da Ponta da Espera/Terminal Hidroviário, localizado no centro histórico de São Luís. A travessia demora um tempo médio de dez a trinta minutos, dependendo da embarcação e do ponto de partida da mesma. O trajeto feito pela embarcação saindo da praia da Ponta D’Areia, o tempo do percurso foi de 27 minutos.

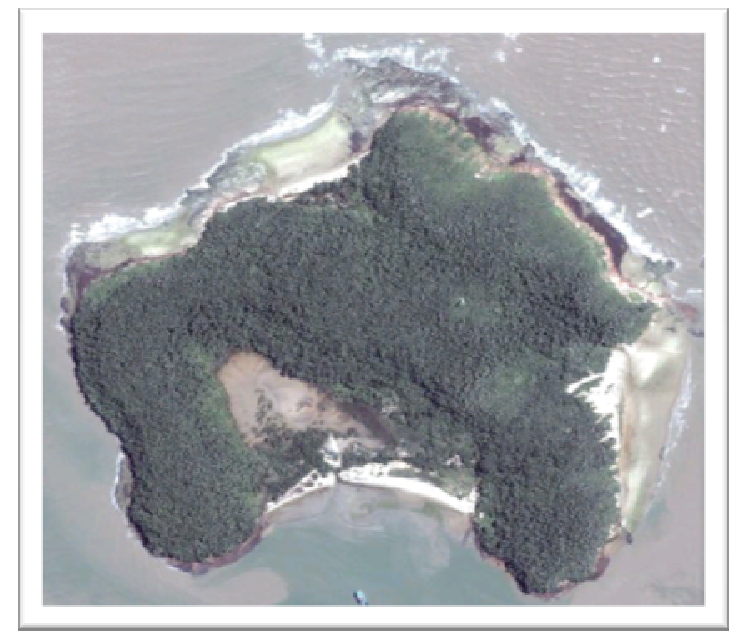

Figura 1: Vista aérea da llha do Medo. Fonte: Google (2011). Figure 1: Aerial view of llha do Medo. Source: Google (2011).

Com a presença de mata fechada, como babaçuais que são responsáveis pela principal atividade de subsistência da Ilha, a extração de babaçu, além da pesca e agricultura, a ilha possui ainda mangues, vegetação de praias, árvores frondosas de mata capoeira e capoeirão, além de uma variedade de solo que vão do argiloso a arenoso, variando de acordo com a topografia local.

Com relação à fauna encontram-se espécies como tatu, paca, bem-tevis, sabiás, dentre outras e espécies típicas de regiões de mangue como insetos, peixes, moluscos, crustáceos (camarão, caranguejo, siri) e aves como garças, guarás, dentre outros. A maioria dessas espécies serve de alimento e renda para a própria população.

Possui ainda um farol da marinha, localizado no alto da llha, o qual os moradores são os responsáveis informais, porém, o mesmo se encontra desativado por cerca de seis meses desde a realização da pesquisa em novembro de 2011.

Hoje a ilha conta com a moradia de doze famílias, possuindo doze casas no total, as quais os moradores revezam suas moradias na ilha do Medo e na cidade de São Luís, devido às necessidades dos componentes mais novos da família, que a ilha não supre, como escolas, empregos fixos, entre outros.

De acordo com os relatos do senhor Manoel da Silva de 64 anos, um dos moradores mais antigos e assíduos da ilha do Medo, o local começou a 
ser habitado pela família do senhor Raimundo Nonato Santos Alves, 56 anos que já habita a ilha há mais de 40 anos.

Manoel da Silva, juntamente com sua família, vieram do município de Cajapió (MA) e acabaram chegando à ilha do Medo por motivos de trabalho com a pesca, onde deram início ao povoamento junto com a família do seu Raimundo Nonato Santos Alves. Atualmente moram duas famílias no local (Figura 2), em residências diferentes, uma de Manoel da Silva e outra que pertence ao seu irmão.

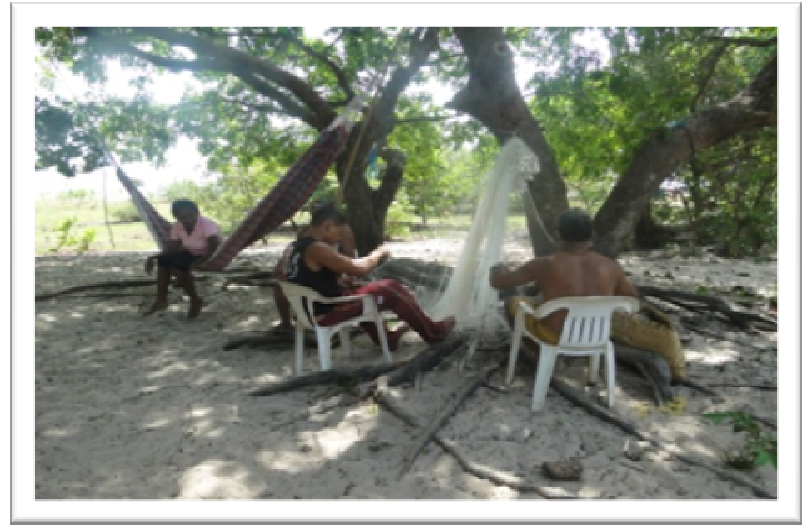

Figura 2: Família de pescadores. Fonte: Produção da autora.

Figure 2: Family of fishermen. Source: Production of the author.

Com poucos habitantes, a llha não é dotada de infraestrutura básica adequada, é carente em todos os aspectos, o que nos leva a conclusão da dificuldade de moradia e visitação ao lugar, que não possui energia elétrica, rede de esgoto, nem água encanada, que na improvisação, os oradores conseguiram pequenos poços e fontes para abastecer toda a ilha.

O abastecimento da ilha também é realizado através de captação de água no poço localizado na Ponta da Espera, pois a água da ilha já não se encontra em plenas condições de uso, pois, segundo o morador Raimundo Nonato, uma espécie de planta cultivada próximo aos poços fez com que a água dos mesmos ganhasse uma cor avermelhada, causando receio nos moradores para utilização da água para beber e cozinhar.

Durante as entrevistas, verificaram-se três insatisfações básicas dos moradores quanto a ilha, a primeira trata do julgamento de procedência da ilha, se a mesma pertence a cidade de São Luís ou à Marinha, que dita as regras na ilha, como o número de casas e moradores; a segunda insatisfação trata da presença da empresa Vale, que vem ampliando sua abrangência na área e, segundo os moradores, os prejudicando quanto a pesca, pois, com a ampliação da mesma e a presença de minério, hoje não há uma quantidade suficiente de peixes para a prática da pesca de subsistência, forçando os mesmos a criar outras espécies na ilha, como a galinha, boi, pato e porco; a terceira insatisfação é a falta de interesse de órgãos públicos em melhorar a infraestrutura da ilha.

Sobre a visitação, é realizada principalmente por pesquisadores, biólogos, geólogos, universitários e pessoas que procuram novas alternativas. Na verdade a ilha é um pedaço de terra ainda inexplorado pelas 
agências de turismo. Entretanto, de acordo com o relato do Senhor Manoel da Silva, a ilha já foi mais frequentada há pelo menos cerca de dez anos atrás, quando famílias de visitantes iam de São Luís e permaneciam o final de semana, gerando renda aos moradores.

Foi verificado o desejo dos moradores em receber turistas na ilha, de acordo que seja de forma ordenada, sem perturbações aos moradores e a própria ilha.

\section{Metodologia}

O início da pesquisa realizou-se através de um estudo a partir da obtenção de informações por meio de pesquisa bibliográfica. Segundo AnderEgg (1978, p.28), "a pesquisa é um procedimento reflexivo, sistemático, controlado e crítico que permite descobrir novos fatos ou dados, relações ou leis no campo atual do conhecimento humano".

A pesquisa tem caráter descritivo que na visão de Pizam (1994, p.97) conceitua como "a descrição sistemática, objetiva e precisa das características de uma determinada população ou área de interesse" e apresentação de abordagem qualitativa. A partir desta análise foi estabelecido um caráter de proposta à pesquisa, a qual tem como objetivo apresentar soluções para algum tipo de problema organizacional já diagnosticado, anteriormente, buscando um estudo de viabilidade de planos alternativos, de concepção e implementação, para a solução de problemas organizacionais (MARTINS; LINTZ, 2000).

O local de execução da pesquisa deu-se na cidade de São Luís, uma Ilha pertencente à costa marítima da cidade, conhecida como llha do Medo. O universo estudado foi formado pelos responsáveis dos atrativos turísticos e a amostra deu-se por acessibilidade, ou seja, os elementos foram selecionadas pela facilidade de acesso a eles.

Os instrumentos da coleta de dados foram à observação e a entrevista. Neste trabalho foi utilizada a semiestruturada, que é aquela em que o entrevistador formata previamente as perguntas, seguindo um roteiro, porém sem estar preso a ele, as perguntas feitas ao entrevistado são determinantes (MARCONI, 1999).

Quanto a observação esta deu-se mediante roteiro preliminar, onde se equipamento fotográfico para resultar em documento de pesquisa. A coleta de dados relacionados à análise das localidades mencionadas acima, ocorreu, também, através da observação e análise do local e seu entorno, com auxílio do equipamento fotográfico para resultar em documento de pesquisa. A pesquisa empírica foi realizada em novembro de 2011.

\section{Proposta para a Ilha do Medo}

O termo turismo de sol e praia passou a ser empregado para uma variedade de ambientes, considerando-se como praia a área situada ao longo de um corpo de água, constituída comumente de areia, lama ou diferentes tipos de pedras, abrangendo as praias marítimas, fluviais e lacustres (margens de rios, lagoas e outros corpos de água doce) e praias artificiais 
(construções similares às praias naturais à beira de lagos, represas e outros corpos d' água) (BRASIL, 2009).

O segmento de sol e praia está associado ao número de horas de sol anual dos lugares, o que gera uma concentração muito grande de turistas nacionais ou internacionais nos destinos nas épocas de mais sol.

Historicamente, o segmento tem sido associado ao turismo de massa, por concentrar um grande número de pessoas na mesma época e em um só lugar. Apresenta altas taxas de sazonalidade, o que traz, como consequência, uma demanda concentrada nos meses de verão ou estiagem (no caso das praias fluviais) e em períodos de férias ou feriados prolongados (BRASIL, 2009).

Constituir um perfil único do turista de sol e praia é um desafio, pois este segmento está coligado a um circuito de atividades e dinâmicas distintas ao longo do território. É importante entender os princípios básicos da eleição da destinação entre os distintos grupos de consumidores, caracterizando, assim, as necessidades, desejos e satisfações de cada grupo, de forma detalhada (BRASIL, 2009).

São percebidas são algumas características comuns aos turistas e usuários do segmento de sol e praia, motivados pelo desejo de descanso, práticas esportivas, diversão, novas experiências e busca de vivências e interação com as comunidades receptoras.

Várias acepções têm sido utilizadas para o segmento de sol e praia, mas para fins de formulação de políticas públicas, considera-se o segmento denominado como: Turismo de Sol e Praia constitui-se das atividades turísticas relacionadas à recreação, entretenimento ou descanso em praias, em função da presença conjunta de água, sol e calor.

A partir da análise do segmento, percebe-se a potencialidade da Ilha do Medo em receber um projeto turístico voltado para as características do turismo de Sol e Praia, pois, possui um ambiente propício a recreação e lazer, além do favorecimento do clima do estado do Maranhão que permite um grande período referente a sazonalidade, já que possui o clima verão como predominante.

A proposta se daria em melhorias a infraestrutura básica como energia, rede de esgotos ou processos alternativos de manejo de resíduos, afim de facilitar a estadia do turista na Ilha. A capacitação dos moradores para a prática de atividades relacionadas ao turismo, como um guia local que auxilie algumas atividades já existentes na ilha, como as trilhas locais para visitação ao farol e visitar as praias que rodeiam a ilha.

Outra capacitação dada aos moradores pode ser relacionada a área de culinária típica (Figura 3) do estado do Maranhão, para que a partir daí a atividade possa render lucros a comunidade local. 


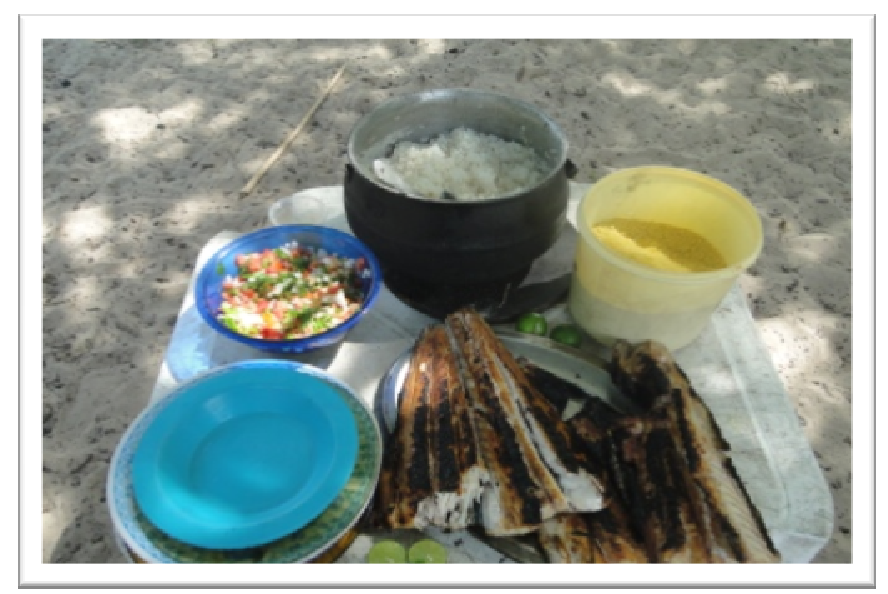

Figura 3: Culinária local. Fonte: Produção da autora.

Figure 3: Local cuisine. Source: Production of the author.

São consideradas atividades turísticas o conjunto de atividades e serviços gerados em função do turismo, ou seja, no caso do turismo de pesca, da viabilização da prática da pesca amadora aos indivíduos que se deslocam a partir de sua residência habitual (BRASIL, 2009). Esse conjunto envolve a oferta de equipamentos, produtos e serviços, tais como:

a) Operação e agenciamento - serviços de operação de viagens, excursões, organização, contratação e execução de programas ou itinerários, além de recepção e assistência ao turista;

b) Transporte - serviços de deslocamento de pessoas ou carga em veículos ou embarcações até as regiões de pesca;

c) Hospedagem - hotel, camping, barco-hotel, pousada, dentre outros;

d) Alimentação - serviços culinários ofertados nos barcos de apoio à pescaria, restaurantes, cafeterias, bares e similares;

e) Recepção e condução - guias e condutores de turismo especializados no segmento e conhecedores dos pontos de pescaria, responsáveis por acompanhar, orientar e transmitir informações a pessoas ou grupos;

f) Eventos - competições de pesca, palestras, festas, encontros relacionados ao tema;

g) Material para pesca - iscas, varas, molinetes etc.;

h) Outras atividades complementares que existam em função do turismo (BRASIL, 2009, p.140).

Após compreender a definição do termo atividades turísticas quando inserido ao conceito de turismo de pesca, resta refletir sobre o termo pesca amadora.

O IBAMA (2009) define a pesca amadora como aquela praticada por brasileiros ou estrangeiros com a finalidade de lazer, turismo e desporto, sem finalidade comercial. (Art. $2^{\circ}$ da Portaria №4, de 19 de março de 2009). A pesca amadora, portanto, não envolve, necessariamente, a devolução do peixe à água, atitude relacionada ao conceito de pesca esportiva.

A pesca esportiva é uma modalidade da pesca amadora em que é obrigatória a prática do pesque e solte, sendo vedado o direito à cota de transporte de pescados, prevista na legislação. Portanto, ela diz respeito a uma modalidade em que se devolvem à água todos os peixes capturados por 
meio da prática do pesque e solte, possibilitando a sua sobrevivência (BRASIL, 2009).

Em ambos os casos, o conhecimento e o respeito à legislação vigente são fundamentais para que a atividade não se transforme em um problema para o turista de pesca. Nesse sentido cabe, aos fornecedores dos serviços turísticos prestarem as informações necessárias ao turista, visando garantir o respeito à legislação.

A pesca esportiva pode ser outro segmento a ser abordado na ilha (Figura 4), já que a mesma possui potencial para a atividade, se tratando de ilha, possui locais que podem ser adaptados afim de proporcionar maior segurança ao visitante. A construção de um píer, para captação de embarcações pode ser prolongado afim de estabelecer locais para 0 praticantes da pesca na localidade. O píer poderia ser localizado no lugar em que as embarcações costumam desembarcar os passageiros (Figura 5).

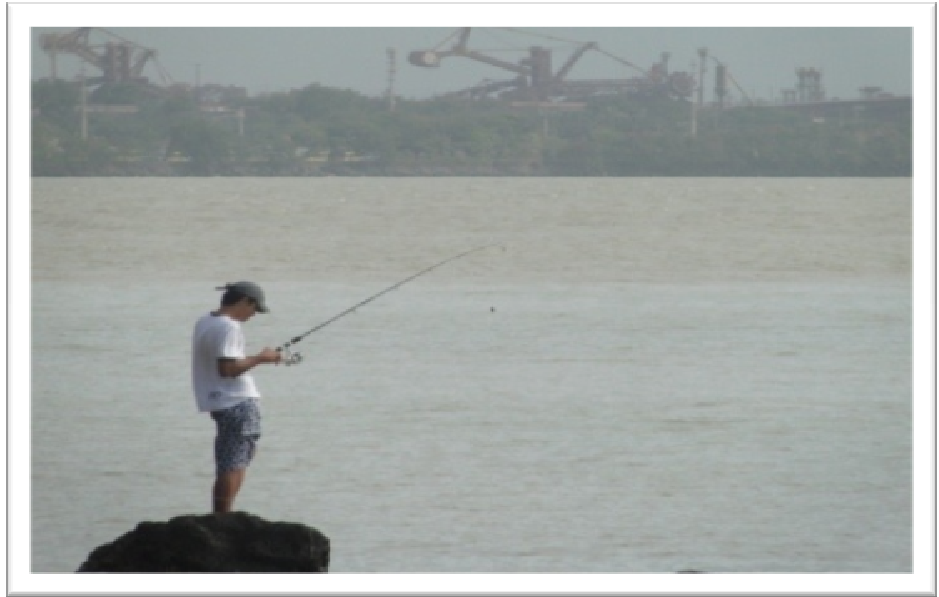

Figura 5: Prática da pesca esportiva. Fonte: Produção da autora.

Figure 5: Practice of sport fishing. Source: Production of the author.

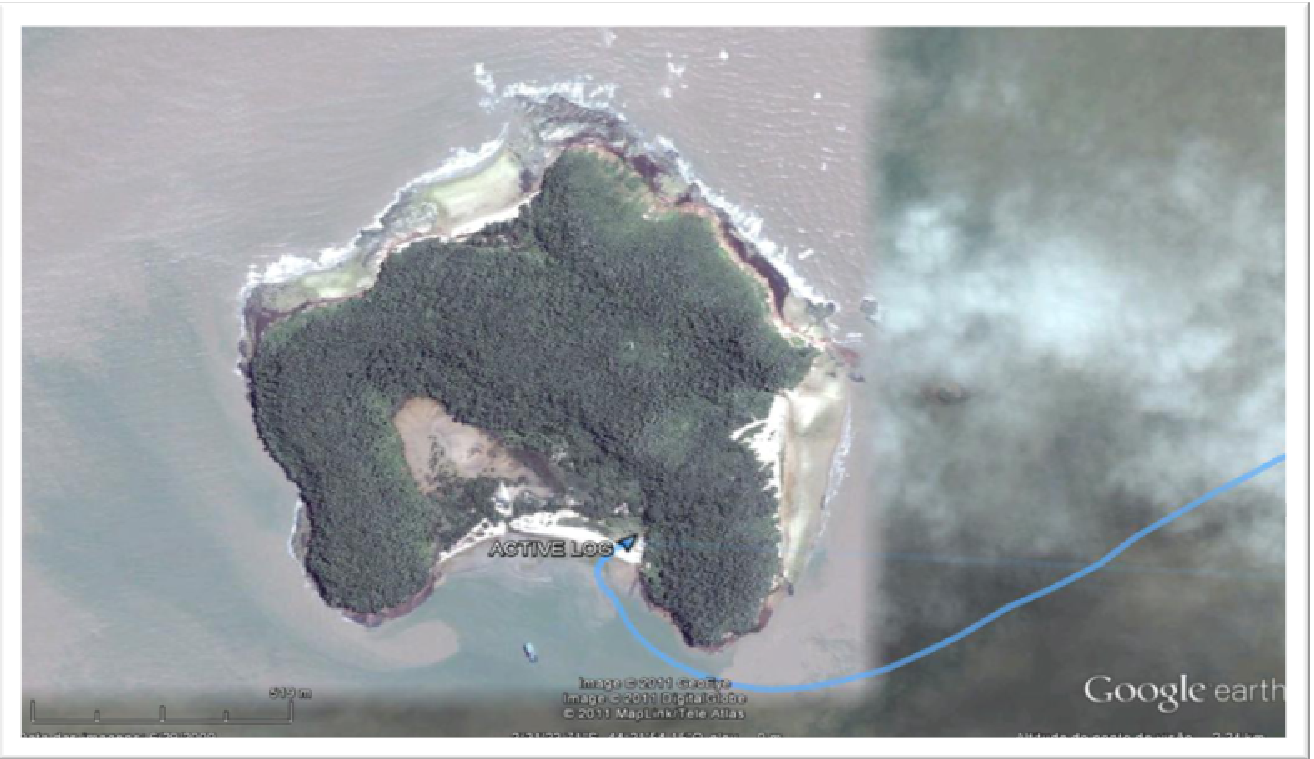

Figura 5: Sugestão de local para o píer na llha do Medo. Fonte: adaptado de Google (2011). Figure 5: Suggested location for the pier in llha do Medo. Source: adapted from Google (2011). 
A capacitação dos moradores para servirem de instrutores de pesca é de fundamental importância, devido à geração de renda para as famílias residentes na localidade, além de estabelecer um contínuo contato com uma atividade característica da comunidade, assim preservando-a.

Podem ainda, os produtos e serviços estabelecidos na prática do turismo de base comunitária que é, ainda, um segmento pouco conhecido, cientificamente, entretanto tem sido visível como um campo de estudo e como uma atuação mais efetiva por parte do poder público, no que tange à incentivos:

\begin{abstract}
[...] em maio de 2008, foi anunciado publicamente o lançamento do Edital 01/2008 do Ministério do Turismo voltado para o financiamento específico de projeto de Turismo de Base comunitária. Embora não se possa definir como uma política pública federal, esse foi um marco das primeiras ações do poder público federal em apoio a um outro modelo de turismo onde as populações tradicionais, os trabalhadores rurais, os pescadores, os representantes das culturas indígenas são os principais protagonistas (MINISTÉRIO DO TURISMO, 2009b, p.15).
\end{abstract}

Assim, o turismo comunitário é entendido por toda configuração de organização empresarial amparada na particularidade e na autogestão sustentável dos recursos patrimoniais comunitários, assim como as técnicas de colaboração e igualdade no ambiente de trabalho e na distribuição dos benefícios gerados pelos serviços turísticos, com a particularidade do turismo comunitário, sua dimensão humana e cultural e o objetivo de incentivar o diálogo entre iguais e encontros interculturais de qualidade com nossos visitantes, na perspectiva de conhecer e aprender com seus respectivos modos de vida (BRASIL, 2009b)

Fundamentado em princípios de solidariedade, o turismo comunitário está entre as atividades que movimentam a localidade juntamente com a comunidade, por não se tratar de concorrência, adversários, e sim utilizar a comunidade com um todo, como empreendedores e protagonistas do local (ECODESENVOLVIMENTO, 2011).

A partir destes conceitos sobre o turismo de base comunitária, podese, também, adequar as atividades já citadas acima para a qualificação do turismo nesta nova temática, ainda não oficial, do Ministério do Turismo, como a atividade da pesca, culinária local, trilhas, entre outras atividades, prezando sempre pela sustentabilidade ambiental e social da localidade.

\title{
Conclusão
}

A fim de permitir a condução apropriada da utilização do turismo, fazse necessária a incorporação do planejamento e projeto turístico como instrumentos de organização e estruturação de espaços turísticos. O planejamento e os projetos são os meios pelo quais se pode elaborar e direcionar políticas públicas com 0 intuito de regularizar e melhorar 0 
aproveitamento do turismo, independente de qual seja sua utilização. Permite ainda a construção de cenários e futuros desejados pelos seus idealizadores.

No âmbito municipal a relação da economia do turismo com a necessidade de planejamento da atividade torna-se visível, pois é nesta unidade territorial que se encontram efetivamente os recursos turísticos e os atrativos que possibilitam o interesse e as deslocações dos turistas. A intervenção dos municípios nas políticas de desenvolvimento do turismo torna-se, assim, imprescindível e fundamental para promoção e ampliação dos benefícios da atividade turística local.

A cidade de São Luís (MA), por sua vez, possui os recursos e o potencial turístico necessários para fomentação da atividade turística na localidade. No entanto, alguns atrativos ainda não foram mapeados ou simplesmente não foram transformados em produtos, por isso, neste trabalho, utilizou-se de alguns atrativos e propôs-se a formatação dos mesmos como novas opções para os roteiros da cidade.

Para que um destino turístico mantenha-se competitivo é necessário que inove cada vez mais, pois a concorrência no mercado nacional e internacional é alta. Além disso, a qualidade exigida hoje pelo turista deve ser refletida no produto formatado.

Dessa maneira, espera-se também contribuir para o melhor posicionamento do destino São Luís, juntamente com os produtos turísticos formatados no mercado e para o atendimento às novas demandas do turista.

\section{Referências bibliográficas}

ANDER-EGG, E. Introdución a lãs técnicas de investigación social. Buenos Aires: Humanitas, 1978.

BOULLÓN, R.C. Planejamento do espaço turístico.Tradução: Josely Vianna Baptista. Bauru/SP: Edusc, 2002.

BRASIL. Ministério do Turismo. Departamento de Estruturação, Articulação e Ordenamento Turístico, Coordenação Geral de Segmentação. Segmentação do turismo e o mercado. Brasília; DF, 2010.

BRASIL. Secretaria de Políticas de Turismo, Estruturação de Produto Turístico. Programa de qualificação a distancia para o desenvolvimento do turismo: curso de segmentação do turismo. Brasília; DF: MTUR; Florianópolis: SEAD/UFSC. 2009a.

BRASIL. Ministério do Turismo. Bartholo, Roberto; Sansolo, Davis Gruber e Bursztyn Ivan : organizadores. Turismo de Base Comunitária: diversidade de olhares e experiências brasileiras. Letra e Imagem. Brasília - DF. 2009b.

CAMPOS, A.M.N. O turismo e a educação frente às novas tecnologias. 2005. Disponível em: <http://www.ivt-ri.net/caderno/cvt18 08.pdf> Acesso em: 2 de nov. 2011.

CERRO, F. La evaluación del potencial turístico en un proceso de planificación: el Canal de Castilla. Estudios turísticos, Madrid, n.116, 1992. 
CUNHA, L. Economia e política do turismo. Lisboa: McGraw-Hill, 1997.

DIAS, R. Introdução ao turismo. São Paulo: Atlas, 2005.

ECODESENVOLVIMENTO. Turismo comunitário cresce no Brasil. São Luís, 2011. Disponível em: $<$ http://www.ecodesenvolvimento.org.br/noticias/turismo-comunitario-cresceno-brasil>. Acesso em: 20 de dez. de 2011.

GOELDNER, C.; RITCHIE, J.R.B.; McINTOSH, R. Turismo: princípios, práticas e filosofias. Tradução de Roberto Cataldo Costa. Porto Alegre: Bookman, 2002.

IBAMA. Instrução normativa n96, de 30 de março de 2006. Brasília, DF, 2006.

IGNARRA, L.R. Fundamentos do turismo. São Paulo: Pioneira, 1999.

MARCONI, M.A. Técnicas de pesquisa: planejamento e execução de pesquisas, amostragem e técnicas de pesquisa, elaboração, análise e interpretação de dados. São Paulo: Atlas, 1999.

MARTINS, G.A.; LINTZ, A. Guia para elaboração de monografia e trabalho de conclusão de curso. São Paulo: Atlas, 2000.

MARUJO, M. Turismo e comunicação. Castelo Branco: RVJ editores, 2008.

OMT. Panorama do turismo internacional em 2009. Brasília, DF, 2011.

PANOSSO NETTO, A.; GAETA, C. (Organizadores). Turismo de experiência. São Paulo: Senac, 2010.

PIPEROGLOU, J. Identification and definition of regions in greek tourist planning. Regional Science Association. 1967.

PIZAM, A. Planning a tourism research Investigation. New York: John Wiley \& Sons, 1994.

PROMON BUSSINESS AND TECHNOLOGY. Gerenciamento de projetos. Disponível em:<http://www.promon.com.br/portugues/noticias/download/PBTR\%20GE para\%20web.pdf>. Acesso em: 2 nov. 2011.

RUCHMANN, D.V.M. Turismo e planejamento sustentável: a proteção do meio ambiente. 5 ed. Campinas, SP. Papirus, 1999.

TRIGO, L.G.G. Turismo e qualidade: tendências contemporâneas. Campinas, SP: Papirus, 1993.

WAINBERG, J. Turismo e comunicação: a indústria da diferença. São Paulo: Contexto, 2003. 
Saulo Ribeiro dos Santos: Universidade Federal do Maranhão, São Luís, MA, Brasil.

E-mail: saulosantosma@uol.com.br

Link para o currículo Lattes: http://lattes.cnpq.br/6334574563260950

Paloma Araújo Pinto: Universidade Federal do Maranhão, São Luís, MA, Brasil.

E-mail: palomaaraujopinto@gmail.com

Link para o currículo Lattes: http://lattes.cnpq.br/7904283579429076

Protásio Cézar dos Santos: Universidade Federal do Maranhão, São Luís, MA, Brasil.

E-mail: labcom19@yahoo.com.br

Link para o currículo Lattes: http://lattes.cnpq.br/8366575648240693

Data de submissão: 02 de julho de 2012

Data de recebimento de correções: 02 de julho de 2012

Data do aceite: 25 de julho de 2014

Avaliado anonimamente 